This item was submitted to Loughborough's Research Repository by the author.

Items in Figshare are protected by copyright, with all rights reserved, unless otherwise indicated.

\title{
Healthcare designers' use of prescriptive and performance-based approaches
}

PLEASE CITE THE PUBLISHED VERSION

http://dx.doi.org/10.1080/17452007.2016.1212692

PUBLISHER

(c) Taylor \& Francis

VERSION

AM (Accepted Manuscript)

\section{PUBLISHER STATEMENT}

This work is made available according to the conditions of the Creative Commons Attribution-NonCommercialNoDerivatives 4.0 International (CC BY-NC-ND 4.0) licence. Full details of this licence are available at: https://creativecommons.org/licenses/by-nc-nd/4.0/

\section{LICENCE}

CC BY-NC-ND 4.0

\section{REPOSITORY RECORD}

Wanigarathna, Nadeeshani, F. Sherratt, Andrew D.F. Price, and Simon A. Austin. 2019. "Healthcare Designers' Use of Prescriptive and Performance-based Approaches". figshare.

https://hdl.handle.net/2134/22095. 


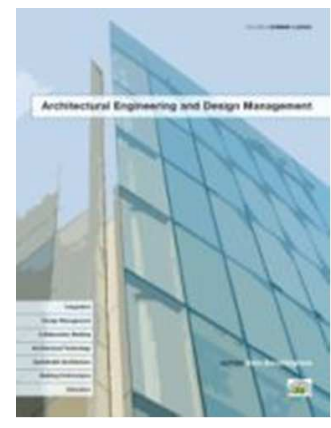

\section{Healthcare designers' use of prescriptive and performance- based approaches}

\begin{tabular}{|r|l|}
\hline Journal: & Architectural Engineering and Design Management \\
\hline Manuscript ID & AEDM-2016-0016.R2 \\
\hline Manuscript Type: & Original Article \\
\hline Keywords: & $\begin{array}{l}\text { healthcare built environments; evidence; designing; performance-based } \\
\text { specification; prescriptive specification }\end{array}$ \\
\hline \multicolumn{2}{|c}{} \\
\hline
\end{tabular}

SCHOLARONE ${ }^{\mathrm{m}}$

Manuscripts 


\title{
Healthcare designers' use of prescriptive and performance-based
} approaches

\begin{abstract}
In the UK, healthcare built environment design is guided by a series of long established design standards and guidance issued by the Department of Health. More recently, healthcare design focus has broadened to encompass new approaches, supported by large bodies of credible research evidence. It is therefore timely to rethink how healthcare design standards and guidance should be best expressed to suit 'designerly ways' of using evidence, to improve their use and effectiveness in practice. This research explored how designers use performance and prescriptive approaches during the healthcare design process. Three in-depth healthcare built environment case studies were used to explore how designers employed such approaches during the design of selected exemplar design elements. Results show that design elements in the pre and conceptual design phases significantly employed performance based approaches, and due to project-unique circumstances, prescriptive solutions were often significantly modified based on performance criteria. For design elements in the detailed and technical design phases, there was significant use of solutions based on prescriptive approaches, whilst performance-based criteria were used to evaluate design solutions. This research proposes a performance-based, specification driven healthcare design with supplementary prescriptive specifications provided for optimum healthcare environment design.
\end{abstract}

Keywords: healthcare built environments; evidence; designing; performancebased specification; prescriptive specification

\section{Introduction}

Hospital design has traditionally focused on efficiency, cost and clinical functionality (Gesler et al., 2004). Similar to many elements of the built environment, the healthcare design process draws on various sources of evidence including but not limited to formal education, personal and colleagues' knowledge and experience, common sense, intuitions and personal interpretations (Hamilton, 2003, Tetreault \& Passini, 2003, Lawson, 2004, Martin \& Guerin, 2007) as well as more formal design guidance 
(Lafratta, 2006, Hignett and Lu, 2009) which also includes the approach of EvidenceBased Design (EBD). However, even within the constraints of EBD there is still discussion and debate as to what actually constitutes evidence. For example Dijkstra et al (2006), Huisman et al. (2012) and Salonen et al. (2013) to name but a few, have been extremely strict as to what could be considered as 'evidence', and claim only scientific research derived through randomised controlled trials is permissible, whilst other scholars' definitions are much looser, for example Hamilton and Watkins (2009) “....current best evidence from research and practice...." and Newhouse et al's (2007 cited in Stichler 2010) “....best available scientific evidence with best experiential evidence of practitioners..." both permit the inclusion of practical experience as evidence alongside findings grounded in traditional empirical research.

Yet despite this relative ambiguity of what 'evidence' can constitute within this specific context, what is perhaps of equal importance is how such evidence is used by designers; how it is mobilised in 'designerly ways' (see Cross, 2001 and later for further description) by those engaging in the creation of our healthcare built environments ,something which remains relatively under-researched. A better understanding of how evidence in its many forms is used by designers in practice, through both performancebased and prescriptive-based approaches, can in turn help optimise how new and emerging evidence is included within future design guidance.

This paper presents an empirical examination, drawing on three case study projects, of how healthcare designers draw on evidence, through designerly ways, in the process of healthcare built environment design. Evidence within this study is considered as either based on experience, found within formally produced design guidance or more explicitly grounded in academic research findings, or indeed a combination of all three, creating a naturally broad and inclusive definition which 
enables the process of design to be explored in depth. It is hoped that in taking a practice-based approach with due recognition of designerly ways, this research can contribute to improvements within the process of healthcare design, and also provide useful insights to help develop an 'ideal balance' of prescriptive and performance specification within this specific built environment context.

\section{Background}

In the UK, the design of healthcare projects is guided by a long-established set of design standards, guidance and tools, first developed during the large, centrally financed national hospital building programme of the 1960s (Lindahl, et al., 2010). This design guidance has been developed and re-issued by the UK Department of Health at regular intervals over the last 50 years.

Formal design guidance often comprises a mix of two main approaches: prescriptive-based or performance-based, contained within formal specifications.. According to the British Standards (BS) definitions (part 3 clause 8.5.4) prescriptive specifications are 'the specifications which set down the characteristics of a product in terms of its size, shape, materials and other dimensions' whist performance specifications are 'the specifications which set down the characteristic functions a product has to perform'. In simple terms, prescriptive specifications are able to prescribe readily available design solutions, that could potentially be adopted or adapted, for example 'use $\mathrm{X}$ if $\mathrm{Y}$ '. Performance-based specifications instead set performance expectations, for example ' $\mathrm{X}$ must meet $\mathrm{Z}$ output', which enables the designer to devise new solutions or make their selection from a range of those available.

It has been argued that performance-based specifications promote innovation within design (Gann et al., 1998, Sexton and Barrett, 2005) and provide the opportunity for superior building quality, because the process allows a choice between a large range 
of approved materials and systems (Haberecht and Bennett, 1999). In the healthcare sector, such innovation can support improvements in patient care through the rapid implementation or integration of new technical or design knowledge within the healthcare facility. It should be noted that failure to use such enhanced design knowledge can lead to the overuse of unhelpful care, the under-use of effective and less expensive care, and errors in execution (Berwick, 2003) which could ultimately cause death, disability, or permanent discomfort (Lansisalmi et al., 2006). Accordingly, in an era where the healthcare sector is seeking constant positive change in terms of care delivery models, technology and medical advances, performance based specifications for design can readily allow beneficial changes to be implemented. However, research has also highlighted that the evaluation of design based on performance specifications can be both difficult and time consuming (Averill, 1998, Baark, 2001), and thus this approach can place an undue burden on the contractor or designer to provide evidence that they have met the required performance specifications (Bowen and Thomas, 1997).

In contrast, prescriptive specifications are more able to promote standardisation in design through the use of previously tested reliable solutions. Particularly in the healthcare sector, standardisation is often encouraged to increase safety and create a measure of reliability, not least through familiarity, within the design and construction process (Reiling et al., 2003, Henriksen et al., 2007, Hignett \& Lu, 2009, Price \& Lu, 2013). However, a prescriptive approach can inhibit innovation (Hoof et al., 2015) and the use of innovative products, which become constrained if the design process is managed and conducted through a framework of tightly prescriptive codes and standards (Sexton and Barrertt, 2005).

Within the UK, formal healthcare design guidance draws on a blend of both prescriptive and performance based evidence. Two key elements within this guidance 
are Health Building Notes (HBNs), which are primarily architectural design guidance, often relevant to early and concept design, and Health Technical Memoranda (HTMs) which set standards and performance criteria, and so are more relevant to detailed and technical design. Design evaluation tools including the Achieving Excellence Design Evaluation Toolkit (AEDET) and A Staff and Patient Environment Calibration Toolkit (ASPECT) are also available to evaluate design, mainly focusing on quality, clinical functionality and healing features of workplace environments. In addition, healthcare designs are also regulated by statutory guidance and UK Building Regulations, similar to any other design for the UK built environment.

More recently, a number of healthcare design approaches have emerged, supported by strong bodies of research and empirical evidence, which also seek to provide guidance, direction and instructions as to how healthcare built environments should best be designed. For example, Evidence-Based Design (EBD) for healthcare is grounded in a considerable body of research that demonstrates how properly designed healthcare built environments can positively impact health outcomes of the building users (see for example, Rubin et al., 1998; Ulrich et al., 2004 Phiri, 2006, Ulrich et al., 2008, Codinhoto et al., 2009). Codinhoto et al. (2009), in their comprehensive review of research-based evidence supporting EBD, established that there are both direct and indirect relationships between built environment interventions and psychological, physiological, physical and behavioural outcomes of the building users. Both industry and academia generally consider the inclusion of such research-based evidence, with its focus on therapeutic benefits, to be a positive way forward in improving the quality of health care delivery overall. However, much of this research-based evidence remains contained within journals and other academic publications, and it has been suggested 
that they are not regularly used or accessed by designers as they carry out their work (Hoof et al., 2015, Emmitt, 2007, Neuckermans \& Fontein, 2002).

There are therefore a number of ways design guidance for healthcare seeks impact to practice. Within the UK particularly this is through both HTMs and HBNs, which are supplemented by different evaluation tools (such as AEDET and ASPECT) and the legislated UK Building Regulations, all of which arguably form a 'canon' of healthcare design guidance used in practice, grounded in both performance and prescriptive specifications. These formal communications are themselves mobilised within the wider context of designers' education, training, knowledge and experience in practice. The position and impact of research-based evidence within this arena is less defined, and indeed because of the nature of its emergence, may only gain impact through serendipitous means.

Within this context, getting the 'right mix' of design information has itself been the subject of a significant body of research, seeking to determine the optimum balance between performance and prescriptive specifications within design guidance. Several initiatives (for example the work carried out by Bowen and Thomas (1997) under the CIB Task Group TG 11, by Bakens et al. (2005) under the Performance Based Building Network; by Bukowski (2002) under the TG 37 and by Meacham (2010) under IRCC Inter-jurisdictional Regulatory Collaboration Committee) have been established over the last two decades, specifically to explore and promote the use of performance-based specifications, grounded in research.

However, their findings have also suggested the importance of prescriptive specifications within a performance-based regulatory system (Bergeron, 2003). It is the balance between the two that is deemed of vital importance; however the 'right mix' of specifications for healthcare design guidance has not been investigated systematically. 


\section{Research Approach: Designerly Ways}

This research took a retrospective approach based on designerly ways. In his seminal article 'Designerly ways of knowing', Cross (2001) argued that design has its own distinct 'things' to know and ways of knowing, thinking and acting. More specifically, he proposes a design knowledge that supports the creation of our world through the employment of knowledge inherent in the process of designing, knowledge inherent in the artefacts of design and their use, knowledge in the process of manufacturing such artefacts, and knowledge gained through instruction in them, all considered within the ongoing processes of reflection and enactment (ibid). It is this complex process that creates a 'designerly way'. The findings of Cross's research have been acknowledge by many, and subsequent research has built on these theoretical foundations, mobilising designerly ways to explore the processes of design.

For instance Demian and Fruchter (2004, 2006a, 2006b) and their colleagues undertook an ethnographic study of knowledge reuse in the architecture/ engineering/construction industry, grounded in designerly ways. They identified the importance of incorporating details related to the context and evolutional history of the developmental process when disseminating best practice solutions, and results of their research were used to develop a 'corporate memory', itself a rich, detailed repository of knowledge in context. Whilst Lawson (2004) identified the importance of the descriptive 'story-telling' form to transmit passive evidence effectively into the design process, claiming that evidence contained in standards and guidance in the form of design solutions are preferred by designers, as opposed to generic rules. Yet despite such research exploring designerly ways in general practice, the importance of considering designerly ways specifically within healthcare building design has been lacking, despite the potential for significant benefits to be gained from its consideration. 
In taking this theoretical position, it can therefore be suggested that if specifications within healthcare design guidance are themselves expressed to suit designerly ways of using such evidence, this will in turn improve both their use and effectiveness in practice.

\section{Research Methods}

\section{Data Collection: Case Studies and Interviews}

This research took a multiple case study approach as described by Yin (2009), to enable the collection of focused, in-depth, rich data.

Three case study projects were identified through industry partners, and were purposively selected, based on the following criteria:

(1) The project had been completed, to enable collection of data related both to the process of designing as well as the operational performance of the building, to enable evaluation of the 'success' of the design in use.

(2) The project had been recently completed, to readily enable access to those involved during the design stage, and to ensure their ability to remember details related to designing the particular facility.

(3) The project had to include clearly identifiable elements which would have necessitated recourse to both performance and prescriptive forms of evidence in their design.

Details of the case study projects can be found in Table 1, and the data were collected over a period of 6 months. As these were retrospective case studies, a limitation of the study was its reliance on memory recall of the interviewees and the accuracy and completeness of documentary records. Careful consideration of the Case Studies (see selection criteria 2 above), collecting data from multiple sources and 
follow-up calls to fill the 'gaps' in any data collected as identified during analysis were taken as measures to improve the validity of data and mitigate the impact of this limitation.

Table 1. Details of case studies [insert near here].

Three initial interviews were conducted with the Design Team Leader of each case study project, in order to explore and identify specific examples where prescriptive and performance-based approaches had been used in the design process. Each interview lasted approximately one hour, and were audio recorded with the consent from interviewees. From this data, a manageable number $(n=8)$ of exemplar design elements were selected for further exploration within each case study project (total $n=24$ ). The criteria for this shortlisting were: comparability of design elements between the three case study projects; representation of the different phases of healthcare design (predesign, conceptual design, detail design and technical design phases); and representation of different types of elements within healthcare built environment design.

The use of a performance-based approach $(n=4)$ was represented by the designing of: single bed room (including en-suite and bed head services panel); ward layout and clinical workstation; window design and ventilation strategy and Communal spaces within the hospital. The use of a prescriptive approach $(n=4)$ was represented by the designing of: an Isolation room, finishes, internal doors, and water service design. These selected exemplar design elements are also able to represent the pre and conceptual design phases, and the detailed and technical design phases within the overall design process.

Subsequently, six further in-depth semi-structured interviews were held to explore each of the design elements with the members of each case study project design team who had worked on the design process of these specific design elements, as 
identified during the initial interviews. Three of the interviews were conducted with the Design Team Leaders of each project, the other three with engineering services designers of each project. The criteria for selecting interviewees was based on their involvement during the design development for the selected 8 design elements and their ability to recall details of the development process. Interviews with design team leaders lasted approximately two and half hours, and the interviews with engineering services designers lasted approximately one hour. Again, the interviews were audio recorded with the consent from interviewees. These in-depth interviews sought to identify how the designers gathered evidence in different forms and explore and illuminate the design development process undertaken to achieve their final design solutions (this has been termed the element story during the analysis).

Documents were also gathered where available, and included meeting minutes, project deliverables, and presentations made to various stakeholders, which provided supplementary data for each element story. Finally, three interviews were also held with the facilities managers of the three case study projects, to determine the performance of the design during the use of three facilities, to provide some measure of elemental design 'success' in operation. Each interview lasted approximately an hour and half and again were audio recorded with the consent from interviewees.

\section{Data Analysis: The Element Stories}

The data were transcribed where necessary and collated to compile element stories for each of the eight design elements within the case study projects. However, during the developmental process it emerged that the data actually contained element stories for the designing of $n=27, n=25$ and $n=26$ (for Case Studies A, B and C respectively) exemplar design elements. For example, the designing of communal areas could itself be divided into three design elements: designing of play areas, waiting space and staff 
rest areas (for Case Studies A and C) and finishes were divided into floor finishes, wall finishes, ceiling finishes (for Case Studies A, B and C).

Directed content analysis (Hsieh and Shannon, 2005) was used to analyse the data and develop the element stories, initially using a pre-determined coding framework, but as the process was undertaken codes were included that emerged from within the data itself. Initially, designing based on a prescriptive approach was categorised as either ado(a)pting guided solutions or ado(a)pting selected solutions. Designing based on a prescriptive approach was categorised into two types, either involving the devising new solutions or the use of constructed design solutions. Details of these pre-determined categorisations can be found in Table 2.

Table 2: Pre-Determined Coding Structure [Table 2 near here]

However, it soon became apparent that the initial coding framework was too simplistic to represent the approach to evidence use in practice. Therefore new codes were developed as part of the analytical process to reflect practice as necessary. Details of the additional codes used within the analysis are presented in Table 3.

Table 3: Final codes for approaches to designing based on prescriptive and performance-based approaches [Table 3 near here]

\section{Findings and Discussions}

\section{Different Approaches to Designing}

The analysis was able to reveal several different approaches to designing found within the three case study projects; a comparison can be found in Table 4.

Table 4: Comparison of the three case studies in their approach to design. [Table 4 near here] 
As shown in Table 4, Case Study A devised solutions based on both performance-based and prescriptive-based approaches. For example, the room layout for Case Study A was devised based on performance requirements. Due to the unique shape of the site and the consequential shape of the building, adopting any existing single patient room layouts as prescribed by the Department of Health (DoH) was impossible. Subsequently, the design team extracted performance criteria for a single patient room from the DoH design guidance, drawing on the design team's collective experience and project requirements to devise three key design solutions through a performance-based approach. Design of the nurse stations, staff rest area and children's play area were also identified as where solutions were devised through a performancebased approach. On the other hand, the design of the windows for the single patient rooms gives an example for the use of a prescriptive approach. The engineering services designer considered three window design options they had previously used in their practice. These were then evaluated to enable the selection of the most suitable design solution based on the performance specifications available within $\mathrm{DoH}$ design guidance and additional performance specifications derived from the project requirements.

Additional elements where a prescriptive approach was employed included the selection of floor, celling and wall finishes, the observation panel in the single patient room door, and the water service design

In contrast, Case Study B significantly used prescriptive evidence (SS or GS). For example designs for bed head service design, staff base design, nurses' call system were all identifiable as prescriptive design solutions adopted from $\mathrm{DoH}$ guidance and solutions previously used by the design team. However the design of the ward layout, en-suite, the percentage of single patient rooms and the door specifications forms some examples of solutions developed through a performance-based approach (DS). 
Similarly, Case Study C also adopted a significant number of prescriptive solutions (SS). Relatively few design elements unique to the project requirements such as the corridors, ward layouts, entrances to the wards, and the location of nurse bases drew on a performance-based approach.

Potential reasons for these differences in practices could be associated with: designers' effort for innovation uptake (for example, observation panel in the door for Case Study A, Nurses' call system in Case Study B); strengths and weaknesses of the design guidance itself (for instance bed head service panel in Case Study A, Single room and en-suite design in the Case Study B); and case unique circumstances that favoured either standard or tailor-made solutions (shape and layout in the ward and single room in cases A and B, location of entrance in Case Study C).

When considered holistically, the findings also show that prescriptive approaches were more frequently used in devising solutions than performance-based approaches. Interestingly, analysis of the element stories revealed that prescriptive solutions used by designers were based mainly on evidence from external sources and not necessarily gathered from in-house sources or formal design guidance documentation. For example the door observation panel in cases $\mathrm{A}$ and $\mathrm{B}$ and the Nurses' call system in Case Study B had been identified during the design team's visits to industrial exhibitions and to other healthcare facilities. The majority of the details related to single-patient rooms had been gathered from published research accessed by clients through research journals and by other members of the design team through systematic reviews and conferences. This suggests that research-based design knowledge may be readily accepted by designers, should it be embedded within formal prescriptive specifications, irrespective of the fact that it is evidence from external sources. It also challenges the notion that designers do not prefer to draw on more 
'academic' sources as claimed by Hoof et al. (2015), Emmitt (2007) and Neuckermans

$\&$ Fontein(2002) to inform the design process, perhaps a consequence of recent dialogues on Evidence-Based Design for healthcare. It should also be noted that, research-based evidence was always employed alongside other forms of evidence such as knowledge and experience when mobilised during the design process.

In a number of occasions (14\%), prescriptive approaches were significantly modified to achieve bespoke solutions (GS+, SS+) and, in a few instances (9\%), initially considered prescriptive evidence was in fact rejected, and alternative solutions were designed (GS/SS > DS) (For example Single room design for cases A and B, door frame design for Case Study A, en-suite for Case Study B). However, this was not necessarily beneficial for the individual design elements, and consequently project operational 'success', as the analysis of the interviews with the facility managers demonstrated. In some instances, through this process of modification or new design, the final design element contained minor failures, in the majority because of the lack of due consideration of project-specific circumstances). For example, the design team had not considered the impact of the noise from the mechanical window opening system on children's sleep. This emphasises the need for a comprehensive evaluation of prescriptive approaches to design prior to implementation, to identify its suitability for the design problem at hand, and to make improvements where appropriate.

On several occasions prescriptive approaches utilising formal design guidance (such as HTMs and HBNs) was considered initially, before the designers moved onto alternative design approaches. In these instances, prescriptive specifications as presented through the design guidance were used as supporting sources of evidence, with the design rationale extracted to form ad-hoc performance based evidence on which design could then be based. This suggested that designers are willing to draw on 
prescriptive specifications from design guidance through their designerly ways, developing and adapting prescriptive evidence as deemed beneficial within the design process. This also highlights the importance of disseminating, where possible, rationales behind prescriptive specifications along with the solutions themselves.

\section{Influence of the Design Phase}

The analysis also identified an association between the phase of the design development (pre and conceptual design, or detailed and technical design) and the approach made to designing, based on the evidence used. This has been illustrated within Table 5 .

Table 5: Frequency of designing based on prescriptive and performance-based approaches during the pre and conceptual design phases and detail and technical design phases [Table 5 near here]

\section{Pre and Conceptual Design Phases}

The majority of design elements related to the pre and conceptual design phase resulted in devised solutions (DS), from performance-based approaches. This is likely to be driven by the need to tailor-make the concept design to project-specific requirements, and perhaps reflects previous research findings which highlighted designers' preference for using active knowledge during the conceptual design phase, in order to devise bespoke solutions.

At these stages, designers claimed to prefer to use prescriptive approaches, where and if available, from formal design guidance (such as HBNs) as a 'starting point' (for instance within the single room design element for Case Studies A, B and C; the En-suite design for Case Studies A and B; and the Nurses' station design for Case Studies A and B). In many instances, designers then deviated from these exemplar solutions due to weaknesses within the examples (as found within the single room 
design for Case Studies A, B and C; En-suite design for Case Studies A and B); or due to project-specific requirements, circumstances and restrictions (as found within the Ensuite design for Case Study B, and the Nurse Station design for Case Studies A and B). Again, prescriptive approaches were used in designerly ways, here as supporting sources of information, with the design rationale extracted to form an ad-hoc performance based approach. This reinforces the importance of incorporating prescriptive specifications within the design guidance for pre and conceptual design phases (primarily HBNs) in designerly-friendly forms that explicate the design rationales for and alongside the specifications, to enhance their utility to this designerly process in practice.

\section{Detailed and Technical Design Phases}

The majority of design elements within the detailed and technical design phases were grounded in a prescriptive based approach (see Table 5), and interviews revealed that in the majority this took the form of innovative solutions identified from within industry (for example the Nurses' call system in Case Study B, the staff base computer in Case Study A, the door observation panels in cases A and C, and the wall finishes for Case study A). On a considerable number of occasions designers used de-facto standards.

Prescriptive solutions used during the detailed and technical design phases were often adopted with little or no improvements or modification and solutions were often simply rejected outright if not deemed suitable. In some occasions where prescriptive solutions were adopted without modification, the final design element ultimately contained what were considered minor failures by the facility managers during the operational phase of the building. The main reason for this could be identified as the lack of evaluation of solutions before adoption. For example the infra-red taps used in the water services design in Case Study $\mathrm{C}$ required frequent battery changes, something 
impractical and excessive from the facility manager's point of view. Therefore, it could be recommended that prescriptive design guidance should be cautiously adopted by design team with due evaluation and consideration of the In-Use phase of the facility. Indeed, further guidance on the evaluation of such prescriptive solutions would be useful to enhance their inclusion in the design process.

In relatively few occasions, notably within Case Study A and Case Study B, the design team did use new design solutions, and significant engagement between designers and the manufacturers of design solutions proved useful in devising bespoke solutions to suit the design requirements (such as the floor finishes and door frame design in Case Study A). For instance, through significant engagement with the manufacturers, the design team of Case Study A devised a bespoke door from to avoid children's fingers being trapped between door and door frame. Here, the importance of providing procedural guidance becomes apparent, to ensure designers give due consideration to project-specific requirements, making the evaluation of design solutions and engagement with supply chain much more beneficial.

Even though the majority of the elements in this phase were developed through a prescriptive approach, perhaps surprisingly prescriptive solutions grounded in formal design guidance was less well utilised. However, these results must be interpreted with caution. Designers of all three Case Studies mentioned that they used formal design guidance during the detail design phases, but these conversations were silent as to specific examples of prescriptive solutions they had adopted; thus making the count for using prescriptive approaches from design guidance (GS or GS+) low in the analysis. However, it could be observed that performance-based data contained in such guidance was heavily utilised by designers to evaluate prescriptive solutions that had been identified externally. These findings emphasise the importance of incorporating 
performance-based specifications within detailed and technical design guidance, which would therefore provide the opportunity to disseminate reliable prescriptive specifications through these forms of guidance.

\section{Discussion}

The findings here are able to provide additional empirical evidence to support previous considerations of the advantages and disadvantages of using performance specifications (Gann et al., 1998; Sexton and Barrett, 2005; Averill, 1998; Haberecht and Bennet, 1999; Baark, 2001; Bowen and Thomas, 1997). All three case studies are able to provide examples where performance standards have stifled innovation (e.g. Case study A - water service design, single room design; Case study B - disposed nurse station design, single patient room and en-suite; Case study $\mathrm{C}$ - design of the ward entrance, single patient room design). The findings also support the suggestion that performance specifications could help to achieve superior building quality (e.g. the finishes as found within all three case studies).

However, in contrast with earlier findings, any instances of ignoring new technologies or innovative design solutions due to a heavy burden on the contractor or engineer to prove that system meets performance standards, as suggested by Baark, (1997) and Bowen and Thomas (1997) could not be identified within this data. It could be argued that the designers' burden to prove compliance with performance criteria is actually an opportunity for the engineers and designers of such solutions to be more competitive in the industry.

The importance of prescriptive approaches and solutions in the attainment of standardisation has also been noted within the literature (Price and Lu, 2013; Hignett and Lu, 2009; Henriksen et al., 2007), yet the findings here did not determine any direct evidence to support this claim. However results do suggest an association between 
prescriptive solutions and standardisation as a measure of reliability through the use of previously tested solutions and, through the identification of failures as a result of the adoption of innovative solutions without due evaluation. In contrast to earlier findings (Hoof et al., 2015), this research did not detect any evidence to claim that prescriptive based approaches do inhibit innovation, in fact prescriptive solutions identified externally served as a mean of innovation uptake during the detail and technical design phases. Although it must be noted that here prescriptive design solutions were taken from healthcare design guidance that was not necessarily mandatory, as opposed to the framework of tightly prescriptive codes referred to by Sexton and Barrertt (2005), and as such retained a measure of flexibility that designers could exploit in practice.

\section{Reflections in practice: Improvement Opportunities for Existing Healthcare Design Guidance}

Taken together, the findings of this research are able to propose an approach to healthcare design guidance grounded in performance-based specification, yet supplemented by prescriptive specifications.

\section{The Driving Force: Performance-Based Specifications}

This research has shown that a performance-based approach is significantly used during pre and conceptual design stages. Even though pre and conceptual design guidance contains performance-based specifications, the Case Studies revealed that designers do not necessarily recognise this within formal guidance; the way they are articulated and structured makes them 'un-user friendly'. For example, the designers of Case Study A compared different products for finishes against the performance specifications as stated in the guidance, which they found comprehensive and from which they could easily extract the necessary information. The designers of Case Study B also took the same 
approach to evaluate alternative single room designs, yet ultimately they developed their own set of performance specifications, since these could not readily be extracted from the guidance. It can therefore be suggested the way performance specifications are articulated within the guidance remains of critical importance.

Furthermore, the results of this research show that performance-based approaches are also used by designers to evaluate prescriptive solutions that have been identified externally. As noted, the need to comprehensively evaluate externally identified solutions is essential for operational 'success', and therefore it can be suggested that formal guidance should be developed to include performance specifications as appropriate, to prevent failures associated with the lack of evaluation of external identified solutions.

\section{Supplementary Sources: Prescriptive Specifications}

According to the findings from the case studies, prescriptive approaches are utilised at all phases of the design process. Similar to the findings by Fox et al (2000) and Gibb (2001), standardisation becomes prominent for products and materials during the technical and detailed design, and this research confirmed the significant use of prescriptive evidence during these design phases. As noted by Emmitt and Yeomans 2008, citing work by Mackinder and Marvin (1982) '...there comes a point where someone with technical knowledge will have to make the design work, including compilation with legislation and best practice'. In the majority of instances, designers that identified prescriptive solutions sourced these from external data provided by industry. There is therefore an opportunity to provide more prescriptive specifications within formal design guidance to support the detailed and technical design phases. However, as LaFratta (2006) reported, there are difficulties in updating design guidance to suit the rapid pace of technological developments. Supporting design guidance with 
an enormous amount of prescriptive solutions may therefore prove impractical and more informal methods of communication may be a more suitable approach for the dissemination of innovative prescriptive solutions to designers. Although not the most frequently used approach within the design process, prescriptive evidence was often used as a 'starting point' during the pre and conceptual design phases. Existing guidance provides significant detail of prescriptive solutions as exemplar solutions, and should continue to do so, but alongside details of their design rationales for designers to elicit as necessary and subject to any subsequent modifications.

\section{Conclusions}

The findings presented here are able to add to a growing body of literature around design knowledge and provide insight as to how designers use prescriptive and performance-based approaches in healthcare design. For design elements in the pre and conceptual design phases, due to project-unique circumstances there is a tendency for designers to devise solutions through a performance based approach, whilst at these stages more prescriptive solutions were often subjected to modifications. During the detailed and technical design phases, the significant use of prescriptive approaches was noticeable, mostly adopted without modifications or rejected as opposed to adaption with modifications. During this phase, designers used performance-based approaches to evaluate prescriptive solutions identified externally.

The appropriate form and mix of prescriptive and performance-based approaches is likely to depend on the sector. An effective balance between the two types of specifications is needed to achieve innovation and standardisation for a risk adverse sector such as healthcare. This research extends our knowledge on the impacts of designerly ways of using prescriptive and performance-based approaches on innovation and standardisation during the different phases of healthcare building designing. 
Performance-based approaches can stifle innovation whilst prescriptive based approaches, used for elements in the pre and conceptual design phases were often subjected to modifications, and thus are able to facilitate innovation through the process of seeking out new ways of assembling or installing elements and components. Yet prescriptive elements within the detail and technical design phases facilitate innovation via use of innovative materials and component parts generally occurs as a result of research and development activities carried out by manufacturers. However, there is often limited opportunity to modify these components during the integration at project level, potentially to the detriment of operational activities, and thus procedural guidance on how to use such specifications would be beneficial.

Although the research presented here is based on UK Case Studies, where healthcare design is supported by a set of national design guidance, it is still relevant to other countries where similar design guidance frameworks are in place or under development, where and the insights presented here can inform the balance of performance and prescription within the healthcare design process, empirically grounded in the designerly ways such approaches are mobilised in practice

\section{References}

Averill, J.D. (1998). Performance-based codes: economics, documentation, and design. UK: Worcester Polytechnic Institute.

Baark, E., (2001). The dynamics of innovation in engineering consultancy services. Proceedings of the Future of Innovation Studies conference, Eindhoven.

Bakens, W., Foliente, G. \& Jasuja, M. (2005). Engaging stakeholders in performancebased building: lessons from the Performance-Based Building (PeBBu) Network. Building Research \& Information, 33 (2), 149-158.

Bergeron, D. (2003). Role of acceptable solutions in evaluating innovative designs, Proceedings of the CIB-CTBUH International Conference on Tall Buildings. 
Berwick, D.M. (2003). Disseminating innovations in health care. JAMA, 289(15), 19691975.

Boling, E. (2010). The Need for Design Cases: Disseminating Design Knowledge. International Journal of Designs for Learning, 1(1), 1-8.

Bowen, R., \& Thomas, R. (1997). TG11 - Performance-based Building Codes. CIB Report 211: Coordinators' Trend Reports: An Anthology of Future Perspectives. CIB: Rotterdam.

Bukowski, R.W. (2002). The Role of Standards In a Performance-based Building Regulatory System. 4th International Conference on Performance-Based Codes and Fire Safety Design Methods. Melbourne: Australia

Cama, R. (2009). Evidence based healthcare design. 1 edn. US: John Wiley and Sons Ltd.

Codinhoto, R., Tzortzopoulos, P., Kagioglou, M., Aouad, G. \& Cooper, R. (2009). The impacts of the built environment on health outcomes. Facilities, 27(3/4), 138151.

Cross, N. (2001). Designerly ways of knowing: design discipline versus design science. Design issues, 17(3), 49-55.

Cross, N. (2007). This is a chapter. In R. Michel. Book title: Design Research Now: From a design science to a design discipline: Understanding designerly ways of knowing and thinking (pp 41-54). Germany: Board of International Research in Design.

Demian, P. (2004). CoMem: Designing an interaction experience for reuse of rich contextual knowledge from a corporate memory. USA: Stanford University.

Demian, P. \& Fruchter, R. (2006a). An ethnographic study of design knowledge reuse in the architecture, engineering, and construction industry. Research in Engineering Design, 16(4), 184-195.

Demian, P. \& Fruchter, R. (2006b). Finding and understanding reusable designs from large hierarchical repositories. Information Visualization, 5(1), 28-46.

Dijkstra, K., Pieterse, M. \& Pruyn, A. (2006). Physical environmental stimuli that turn healthcare facilities into healing environments through psychologically mediated effects: systematic review. Journal of advanced nursing, 56(2), 166-181.

Emmitt, S. (2007). Design management for architects. London: Wiley-Blackwell. 
Emmit, S. \& Yeomans, D. (2008). Specifying Buildings: A Design Management Perspective. Oxford: Elsevier.

Evans, B., 2009. Evidence Based Design. In: L. Lee and P. Lombaerde, eds, Bringing the World into Culture: Comparative Methodologies in Architecture, Art, Design and Science. Academic \& Scientific Publishers, pp. 227-239.

Gann, D.M., Wang, Y. \& Hawkins, R. (1998). Do regulations encourage innovation?the case of energy efficiency in housing. Building Research \& Information, 26(5), 280-296.

Gesler, W., Bell, M., Curtis, S., Hubbard, P. \& Francis, S. (2004). Therapy by design: evaluating the UK hospital building program. Health \& place, 10(2), 117-128.

Gibb, A.G.F. (2001). Standardization and pre-assembly-distinguishing myth from reality using case study research. Construction Management and Economics, 19(3), 307-315.

Haberecht, P.W. \& Bennett, A.F. (1999). Experience with durability assessment and performance-based building codes. Proceedings of the 1st Asia Pacific Conference on Harmonisation of Durability Standards and Performance. Thailand.

Hamilton, D.K. (2003). The four levels of evidence-based practice. Healthcare Design, $3(4), 18-26$.

Hamilton, K., \& Watkins, D.H. (2009). Evidence based design for multiple building types. USA: John Wiley and Sons.

Henriksen, K., Isaacson, S., Sadler, B.L. \& Zimring, C.M. (2007). The role of the physical environment in crossing the quality chasm. Joint Commission Journal on Quality and Patient Safety, 33(Supplement 1), 68-80.

Heylighen, A., Bouwen, J.E. \& Neuckermans, H. (1999). Walking on a thin line-Between passive knowledge and active knowing of components and concepts in architectural design: Between passive knowledge and active knowing of components and concepts in architectural design. Design Studies, 20(2), 211235.

Hignett, S. \& Lu, J. (2009). An investigation of the use of health building notes by UK healthcare building designers. Applied Ergonomics, 40(4), 608-616. 
Hoof, J. V., Rutten, P.G.S., Struck, C., Huisman, E.R.C.M \& Kort, H.S.M. (2015). The integrated and evidence-based design of healthcare environments. Architectural Engineering and Design Management, 11(4), 243-263.

Hsieh, H.F. \& Shannon, S.E. (2005). Three approaches to qualitative content analysis. Qualitative health research, 15(9), 1277 - 1288.

Huisman, E., Morales, E., Van-Hoof, J. \& Kort, H. (2012). Healing environment: A review of the impact of physical environmental factors on users. Building and Environment, 58, 70-80.

Lafratta, A. (2006). An investigation into multi-activity generic spaces in the design of healthcare facilities. (Unpublished MSc thesis). UK: Loughborough University.

Lansisalmi, H., Kivimaki, M., Aalto, P. and Ruoranen, R. (2006). Innovation in healthcare: a systematic review of recent research. Nursing science quarterly, 19(1), 66-72.

Lawson, B. (2004). What designers know. UK: Architectural Press.

Lindahl, G., Phiri, M., Mills, G., Fröst, P., Strid, M. \& Price, A. (2010). Quality innovation \& evidence in healthcare physical environments in England \& Sweden -Establishing a collaborative Roadmap. 3rd Annual conference of the Health and Care Infrastructure Research and Innovation Centre. UK: HaCIRIC.

Martin, C. \& Guerin, D. (2007). Integrating the Use of Research into the Design Process Experience. IDEC 2007, 30(1), 57-67.

Meacham, B.J. (2010). Performance-Based Building Regulatory Systems - Principles and Experiences. Australia: IRCC.

Moore, K.D. \& Geboy, L. (2010). The question of evidence: current worldviews in environmental design research and practice. Architectural Research Quarterly, 14(02), 105-114.

Neuckermans, H. \& Fontein, L. (2002). Nurture and nature of research in architecture, ARCC/EAAE Montreal conference on architectural research proceedings 2002, pp. 23-29.

Phiri, M. (2006). Does the physical environments affect staff and patient health outcomes? UK: Department of Health.

Price, A. \& Lu, J. (2013). Impact of hospital space standardization on patient health and safety. Architectural Engineering and Design Management, 9(1), 49-61. 
Reiling, J., Breckbill, C., Murphy, M., Mccullough, S. \& Chernos, S. (2003). Facility designing around patient safety and its effect on nursing. Nursing Economic, 21(3), 143-147.

Rubin, H.R., Owens, A.J., Golden, G. \& Webber, D.O. (1998). Investigation to determine whether the built environment affects patient's medical outcomes. CA: Center for Health Design.

Salonen, H., Lahtinen, M., Lappalainen, S., Nevala, N., knibbs, L.D., Morawska, L. \& Reijula, K. (2013). Physical characteristics of the indoor environment that affect health and wellbeing in healthcare facilities: a review. Intelligent Buildings International, 5(1), 3-25.

Sexton, M. \& Barrett, P. (2005). Performance-based building and innovation: balancing client and industry needs. Building Research \& Information, 33(2), 142-148.

Stichler, J.F. (2010). Research or Evidence-Based design: Which process should we be using? Health Environments Research and Design Journal, 4(1), 6-10.

Tetreault, M.H. \& Passini, R. (2003). Architects' use of information in designing therapeutic environments. Journal of Architectural and Planning Research, 20(1), 48-56.

Ulrich, U., Zimring, C., Joseph, A. \& Choudhary, R. (2004). The role of the physical environment in the hospital of the 21st century: a once-in-a-lifetime opportunity. Concord, CA: The Center for Health Design.

Ulrich, R.S., Zimring, C.M., Zhu, X., Dubose, J.R., SEO, H.B., Choi, Y.S., Quan, X. \& Joseph, A. (2008). A review of the research literature on evidence-based healthcare design. Health Environments Research \& Design, 1(3), 61-125.

Yin, R.K. (2009). Case study research: Design and methods. Thousand Oaks, CA: Sage Publications. 
2

39

40

Table 1. Details of case studies

\begin{tabular}{|c|c|c|c|}
\hline Project name & Case Study A & Case Study B & Case Study C \\
\hline Type of the facility & A children's hospital & $\begin{array}{l}\text { Non-critical elderly care and } \\
\text { mental health hospital }\end{array}$ & Elderly care facility \\
\hline Project value & f88m & f90m & f10m \\
\hline Type of construction & $\begin{array}{l}\text { A new modular building } \\
\text { within an existing hospital } \\
\text { site }\end{array}$ & A new building on a new site & $\begin{array}{l}\text { A new modular building } \\
\text { within an existing hospital } \\
\text { site }\end{array}$ \\
\hline Clients involvement & $\begin{array}{l}\text { A team of clinicians from } \\
\text { existing hospital dedicated to } \\
\text { redevelopment programme }\end{array}$ & $\begin{array}{l}\text { Members of the Health } \\
\text { Board }\end{array}$ & $\begin{array}{l}\text { In-house facility } \\
\text { management team of the } \\
\text { existing hospital }\end{array}$ \\
\hline Purpose of the facility & $\begin{array}{l}\text { To replace some old facilities } \\
\text { and to increase the capacity }\end{array}$ & $\begin{array}{l}\text { To replace a number of } \\
\text { existing hospitals with three } \\
\text { new facilities to be operated } \\
\text { under a new care model }\end{array}$ & $\begin{array}{l}\text { To increase the capacity to } \\
\text { cope with winter pressure }\end{array}$ \\
\hline
\end{tabular}


Table 2: Pre-Determined Coding Structure

\begin{tabular}{|l|l|}
\hline Type of approach & Pre- determined codes \\
\hline $\begin{array}{l}\text { Prescriptive } \\
\text { approaches to } \\
\text { design }\end{array}$ & $\begin{array}{l}\text { Ado(a)pting guided design solutions (GS): solutions which were chosen from } \\
\text { published standards and guidance. } \\
\text { Ado(a)pting Selected design solutions (SS): solutions which were chosen from } \\
\text { previous experience or from de facto standards but not from published standards and } \\
\text { guidance. }\end{array}$ \\
\hline $\begin{array}{l}\text { Performance- } \\
\text { based approaches } \\
\text { to design }\end{array}$ & $\begin{array}{l}\text { Devised design solutions (DS) - solutions originally devised by the design team to } \\
\text { solve the design problem } \\
\text { Constructed design solutions (CS) - solutions constructed (rather than construed) as } \\
\text { a result of other parts of the design (for instance the size of a single door was } \\
\text { determined by the plant used for the ceiling hoist). }\end{array}$ \\
\hline
\end{tabular}


Table 3: Final codes for prescriptive and performance-based approaches to design

\begin{tabular}{|l|l|l|}
\hline Type of approach & Final codes & Nick name \\
\hline $\begin{array}{l}\text { Prescriptive approaches } \\
\text { to design }\end{array}$ & Guided solution & GS \\
& Guided solution significantly improved & GS + \\
& Selected solution & SS \\
& Selected solution significantly improved & SS+ \\
\hline $\begin{array}{l}\text { Performance-based } \\
\text { approaches to design }\end{array}$ & Devised solution & DS \\
\hline $\begin{array}{l}\text { Use of both prescriptive } \\
\text { and performance-based }\end{array}$ & Guided solution + Selected solution & CS \\
approaches & Guided solution + Devised solution & GS + DS \\
\hline $\begin{array}{l}\text { Change in the form of } \\
\text { approach used }\end{array}$ & Selected solution + Devised solution & SS + DS \\
\hline
\end{tabular}


Table 4: Comparison of the three case studies in their approach to design

\begin{tabular}{|c|c|c|c|c|c|c|c|c|}
\hline \multirow{2}{*}{\multicolumn{2}{|c|}{ Approach to design }} & \multirow{3}{*}{$\begin{array}{c}\text { An example } \\
\text { Ward layout of all three cases were devised by the design team based on case (project) requirements. }\end{array}$} & \multicolumn{3}{|c|}{$\begin{array}{l}\text { Number of design } \\
\text { elements in each case }\end{array}$} & \multirow{3}{*}{$\begin{array}{c}\text { Total } \\
15\end{array}$} & \multirow{2}{*}{\multicolumn{2}{|c|}{$\begin{array}{l}\text { Use of } \\
\text { approach as a } \\
\quad \%\end{array}$}} \\
\hline & & & \multirow{2}{*}{$\begin{array}{c}\mathrm{A} \\
7\end{array}$} & \multirow{2}{*}{ B } & \multirow{2}{*}{$\begin{array}{ll}\mathrm{C} \\
7\end{array}$} & & & \\
\hline $\begin{array}{l}\text { Performance- } \\
\text { based }\end{array}$ & DS & & & & & & $19 \%$ & \multirow{5}{*}{$31 \%$} \\
\hline $\begin{array}{l}\text { approaches to } \\
\text { design }\end{array}$ & $\mathrm{CS}$ & $\begin{array}{l}\text { Shape of the single patient room in the Case Study A was determined by the (odd) shape of the site and } \\
\text { subsequent building. }\end{array}$ & 2 & - & - & 2 & $3 \%$ & \\
\hline \multirow[t]{3}{*}{$\begin{array}{l}\text { Change in the } \\
\text { type of approach }\end{array}$} & $\begin{array}{l}\text { GS+SS> } \\
\mathrm{DS}\end{array}$ & $\begin{array}{l}\text { Based on DH guidance and visited other similar hospitals, Case Study A was initially designed as a } 100 \% \text { single } \\
\text { bed room building. Considering the types of care provided within the hospital, this was then changed to design a } \\
\text { mix of single rooms and shared bed wards. }\end{array}$ & 1 & - & - & 1 & $1 \%$ & \\
\hline & $\mathrm{GS}>\mathrm{DS}$ & $\begin{array}{l}\text { Exemplar en-suit provided in the DH guidance was first considered for Case Study B, after evaluation this was } \\
\text { then devised to suit the type of patients(elderly) catered within Case Study B) }\end{array}$ & - & 4 & - & 4 & $5 \%$ & \\
\hline & $\mathrm{SS}>\mathrm{DS}$ & $\begin{array}{l}\text { Solutions available in the industry to avoid fingers trapped between door frame and door were considered by } \\
\text { Case Study A, none of which satisfied the performance requirement. Design team has then devised a new } \\
\text { solution working collaboratively with a selected manufacturer. }\end{array}$ & 2 & - & - & 2 & $3 \%$ & \\
\hline \multirow{4}{*}{$\begin{array}{l}\text { Prescriptive } \\
\text { approaches to } \\
\text { design }\end{array}$} & GS & $\begin{array}{l}\text { Isolation room design for the Case Study A was adopted from the } \mathrm{DH} \text { design guidance without significant } \\
\text { changes. }\end{array}$ & 1 & - & - & 1 & $1 \%$ & \multirow[b]{2}{*}{$5 \%$} \\
\hline & GS+ & $\begin{array}{l}\text { Decentralised nurse bases were adopted from DH guidance ( } 1 \text { touch down base for two rooms), this was then } \\
\text { modified to include one larger (than prescribed in the DH guidance) nurse base for eight rooms considering the } \\
\text { type of patients treated within the hospital. }\end{array}$ & - & 3 & - & 3 & $4 \%$ & \\
\hline & SS & Most of the floor, wall and ceiling finishes in all three cases. & 8 & 13 & 15 & 36 & $46 \%$ & \\
\hline & SS+ & $\begin{array}{l}\text { A recessed PC was adopted for the Case Study A to avoid PC restricting nurse view into room. An available } \\
\text { solution was selected and this was modified to improve the capacity to suit hospital activities and to include a key } \\
\text { board to help easy use for the nurses. }\end{array}$ & 4 & 2 & 2 & 8 & $10 \%$ & $56 \%$ \\
\hline \multirow[t]{5}{*}{$\begin{array}{l}\text { A combination of } \\
\text { approaches }\end{array}$} & GS+DS & $\begin{array}{l}\text { Detail design inside the single room in Case Study A was design based on the details provided within DH } \\
\text { guidance and client requirements. }\end{array}$ & 1 & - & - & 1 & $1 \%$ & \multirow{5}{*}{$8 \%$} \\
\hline & $\mathrm{GS}+\mathrm{SS}$ & $\begin{array}{l}\text { En-suit of the Case Study B was a design adopted from DH guidance and modified with the solutions (facilities } \\
\text { inside the en-suite such as rails) from the industry to suite elderly patients. }\end{array}$ & - & 1 & 1 & 2 & $3 \%$ & \\
\hline & $\mathrm{SS}+\mathrm{DS}$ & $\begin{array}{l}\text { Details of the single room in the Case Study A was designed based on the solutions seen within the industry and } \\
\text { added features (such as wardrobes) to support care for very young children. }\end{array}$ & 1 & - & - & 1 & $1 \%$ & \\
\hline & $\begin{array}{l}\text { SS+DS+ } \\
\text { GS }\end{array}$ & $\begin{array}{l}\text { Single room layout of the Case Study C was designed based on the exemplar designed given in the DH guidance, } \\
\text { facilities inside the room was adopted from the successful previous project and bed head position was changed } \\
\text { based on client requirements }\end{array}$ & - & - & 1 & 1 & $1 \%$ & \\
\hline & $\mathrm{SS}+\mathrm{GS}+$ & $\begin{array}{l}\text { Water service design of Case Study A was an innovative solution adopted from the industry, incorporated with } \\
\text { local heaters (based on DH guidance) for locations where hotter water is needed. }\end{array}$ & - & 1 & - & 1 & $1 \%$ & \\
\hline & & \multicolumn{7}{|c|}{$\begin{array}{l}\text { Key : DS - Devise a solution, } \mathbf{G S}-\mathrm{Ad}(\mathrm{o}) \text { apt a guided solution, } \mathbf{S S}-\mathrm{Ad}(\mathrm{o}) \text { apt a selected de facto or innovative solution, }{ }^{\text {"+’ }} \text { - Significant moderations made, }>- \text { transition } \\
\text { of approach }\end{array}$} \\
\hline
\end{tabular}

https://mc.manuscriptcentral.com/aedm 
Table 5: Frequency of designing based on prescriptive and performance-based approaches during the pre and conceptual design phases and detail and technical design phases

\begin{tabular}{|c|c|c|c|}
\hline $\begin{array}{l}\text { Form of } \\
\text { evidence }\end{array}$ & $\begin{array}{l}\text { Approach to } \\
\text { design }\end{array}$ & $\begin{array}{c}\text { Instances of } \\
\text { use during the } \\
\text { pre and } \\
\text { conceptual } \\
\text { design phase }\end{array}$ & $\begin{array}{c}\text { Instances of use } \\
\text { during the } \\
\text { detail and } \\
\text { technical design } \\
\text { phase }\end{array}$ \\
\hline \multirow{5}{*}{$\begin{array}{l}\text { Performance- } \\
\text { based } \\
\text { approaches to } \\
\text { design }\end{array}$} & DS & 13 & 2 \\
\hline & $\mathrm{CS}$ & 1 & 1 \\
\hline & $\mathrm{GS}>\mathrm{DS}$ & 2 & 1 \\
\hline & $\mathrm{GS}+\mathrm{SS}>\mathrm{DS}$ & 1 & 0 \\
\hline & $\mathrm{SS}>\mathrm{DS}$ & 0 & 2 \\
\hline \multirow{4}{*}{$\begin{array}{l}\text { Performance- } \\
\text { based } \\
\text { approaches to } \\
\text { design }\end{array}$} & GS & 1 & 0 \\
\hline & GS+ & 3 & 0 \\
\hline & SS & 8 & 27 \\
\hline & SS+ & 4 & 5 \\
\hline \multirow{5}{*}{$\begin{array}{l}\text { A combination } \\
\text { of approaches }\end{array}$} & $\mathrm{GS}+\mathrm{DS}$ & 1 & 0 \\
\hline & $\mathrm{GS}+\mathrm{SS}$ & 2 & 1 \\
\hline & SS+DS & 1 & 0 \\
\hline & $\mathrm{SS}+\mathrm{GS}^{+}$ & 0 & 1 \\
\hline & $\mathrm{GS}+\mathrm{DS}+\mathrm{SS}$ & 1 & 0 \\
\hline \multicolumn{4}{|c|}{$\begin{array}{l}\text { Key : DS - Devise a solution, } \mathbf{G S}-\mathrm{Ad}(\mathrm{o}) \text { apt a guided solution, } \mathbf{S S}-\mathrm{Ad}(\mathrm{o}) \text { apt a } \\
\text { selected de facto or innovative solution, }{ }^{++}-\text {- Significant moderations made, }>- \\
\text { transition of approach }\end{array}$} \\
\hline
\end{tabular}

